\title{
Methylene Blue Adsorption onto Surface Modified Beli (Aegle Marmelos) Fruit Shell Biochar
}

\author{
Perera NW PS ${ }^{1}$, Herath $\mathrm{AC}^{2}$, Gunathilake $\mathrm{C}^{* 3}$, Fernando CA N ${ }^{1,4}$ and Kalpage CS $^{3}$ \\ ${ }^{1}$ Department of Electronics, Faculty of Applied science, wayamba university of sri lanka, Kuliyapitiya, sri Lanka \\ ${ }^{2}$ Department of Physical Science, Faculty of Applied Sciences, Rajarata University of Sri Lanka, Mihinthale, Sri lanka \\ ${ }^{3}$ Department of Chemical \& Process Engineering, Faculty of Engineering,University of Peradeniya, Peradeniya, Sri Lanka
}

${ }^{4}$ Nano-technology Research Laboratory, Department of Nano Science \& technology, Faculty of Applied Science, Wayamba University of Sri Lanka, Kuliyapitiya, Sri Lanka

Received: 無: November 21, 2018; Published: 渄: December 06, 2018

*Corresponding author: Gunathilake C, Department of Chemical \& Process Engineering, Faculty of Engineering, Peradeniya, Sri Lanka, India

\begin{abstract}
Contamination of water bodies from toxic substances pose serious health issues, hence there has been an increasing demand for efficient and low-cost purification technologies. Activated carbon materials, in this respect are of great promise for efficient removal of dyes and heavy metals from contaminated water. The Beli Fruit Shell Activated Charcoal (BFAC) was prepared from low-cost cellulose material of beli fruit shell by one step pyrolysis at a low-temperature profile. The prepared BFBC was characterized by SEM, EDX, TGA and FTIR analysis. BET surface area analysis by N2 adsorption method yielded values of micropore volume, total pore volume, and surface area as $0.16 \mathrm{~cm}^{3} / \mathrm{g}, 0.42 \mathrm{~cm}^{3} / \mathrm{g}$, and $517 \mathrm{~m}^{2} / \mathrm{g}$, respectively. The batch type experiment was carried out to explore Methylene Blue (MB) uptake by BFAC. The influence of physio-chemical parameters such as contact time, initial dye concentration, dosage and $\mathrm{pH}$ of dye solution was studied. The equilibrium data tend to fit Langmuir isotherm. Kinetic studies represented that the chemisorption process follows second -order rate kinetics model. It was found that BFAC adsorbs significantly large amount of methylene blue dye (12.32 mg per $1 \mathrm{~g}$ of adsorbent). Due to the high methylene blue dye sorption capacity, reusability, thermal stability, relatively low cost of starting materials and simple synthesis route justify BFAC composite as a potential and effective candidate for the removal of organic dyes from waste water at ambient temperature.
\end{abstract}

Keywords: Belifruit Shell Biochar; Adsorption; BET; Isotherm; Kinetics; One step pyrolysis

\section{Introduction}

As the demand of humans for more comfort life in health, food, transportation continues to increase, the technological advancement results in environmental degradation in water, soil and air. Aquatic systems are, therefore, heavily polluted by various toxicants including heavy metals, organic dyes, pesticides etc. The removal of these toxicants from contaminated waters is of critical importance as they pose serious health issues in living organisms. Over the past years, various methods have been employed and developed for the decontamination of polluted water based on chemical precipitation, ion exchange and membrane filtration methods [1,2]. High reagent requirement, complexity and high cost being the major drawback of these methods, therefore, the removal of toxicants in water based on adsorption on readily available natural materials has become popular due to its simplicity, low cost and efficiency. In this context, various adsorbents such as activated carbon, activated alumina, silica gel, magnetic grapheme oxide have been extensively reviewed.

Activated carbon is a proven adsorbent for an efficient removal of a range of organic dyes and toxic heavy metals due to huge surface area and the network of submicroscopic pores where adsorption takes place [3-5]. Since commercially available activated carbon is more expensive, alternative cheap carbon-based materials from heat and chemically treated leaves, bark or fruits shell of variety of plants collectively known as biochar are attractive adsorbents for water purification in recent years. Biochar derived from rice straw, Neem leaves, oak, pine, Coconut tree sawdust etc. have shown promising sorption abilities toward heavy metals such as $\mathrm{Pb}, \mathrm{As}, \mathrm{Cu}$, $\mathrm{Cr}$ and organic dyes like methylene blue [6-8]. Biochar is a carbon 
rich, solid product resulting from the pyrolysis of carbonaceous biomass under inert atmospheric and low temperature conditions. Pore size and distribution, acidic functional groups such as carboxy, lactone, and phenolic hydroxy groups are the key sites directly responsible for sorption process. In order to develop these surface functionalities which in turn enhance the absorptive properties, biochar undergoes for various chemical treatment methods such as $\mathrm{KOH}, \mathrm{ZnCl}_{2}$ and $\mathrm{H}_{3} \mathrm{PO}_{4}$ activation prior to use as an absorbent [9-15].

Herein we describe our investigations to check the feasibility of biochar derived from Beli fruit (Aegle marmelos) shell as an efficient adsorbent for methylene blue sorption. Beli trees are widely grown in hillside area of Sri Lanka and other Asian countries and plant parts have more derivatives with medicinal properties and used for making traditional ayurvedic drugs and foods [16]. Adsorption experiments were carried by batch type mode by using methylene blue dye. The batch contact time experiments were used to determine the adsorption rate. All kinetic parameters were then estimated. The results will be valuable for future eco-friendly application of BFBC in color removal from waste water.

\section{Experimental}

\section{Materials}

Phosphoric acid was purchased from Fisher scientific UK. Methylene Blue was obtained from Cangzhou Xincheng Weiye Chemical Co., Ltd, China in $70 \%$ purity.

Table 1: Preparation variables of activated bio chart.

\begin{tabular}{|c|c|c|c|c|}
\hline Product code & Source of biochar & Nature of activation & Temperature/ oC & Time/min \\
\hline PFBC & Palmyra Fiber & KOH treated & 420 & 15 \\
\hline CSBC & Coconut Shell & Carbonization & 450 & $\mathrm{~N}_{2}$ flow \\
\hline CABC & Commercial & Physical & 900 & $\mathrm{~N}_{2}$ flow \\
\hline
\end{tabular}

\section{Preparations}

Matured Beli was collected from the western province in Sri Lanka. Cornel of the fruit was removed and the shells were cut into small pieces and washed several times with distilled water and soap flexed to remove adhered contaminations from its surface. After ultrasonically washing with distill water to remove excess chemicals, finally dried at $80^{\circ} \mathrm{C}$ in the muffle furnace for $5 \mathrm{~h}$. Before pyrolysis, the raw shells were ball milled at $450-500 \mathrm{rpm}$ for 05 minutes and the micro level particles were treated with 1.5 $\mathrm{M} \mathrm{H}_{3} \mathrm{PO}_{4}$ for 15 minutes at $360^{\circ} \mathrm{C}$. Heating rate of $10^{\circ} \mathrm{C}$ min- 1 was maintained under nitrogen atmosphere and allowed to cool down to room temperature followed by washing thoroughly with distilled water and dried in the muffle oven at $105^{\circ} \mathrm{C}$ for 1 hour (BFBC). Other biochar products were also prepared under the prescribed conditions given in the Table 1 . In order to determine the activity level of the each Beli activated carbon samples, iodine number was determined according to the standard test method ASTM D 4607.

\section{Characterization}

Proximate analysis of adsorbent, properties such as moisture content, ash content, volatile content, thermogravimetric measurements were recorded on TGA Q-500 analyzer (TA Instruments, Inc., New Castle, DE, USA). Thermogravimetric (TG) profiles were recorded from 25 to $800^{\circ} \mathrm{C}$ under nitrogen atmosphere with a heating rate of $10^{\circ} \mathrm{C} / \mathrm{min}$ using a high-resolution mode. The weight of each analyzed sample was typically in 10-20 mg range. Iodine number was determined using ASTM D 4607standard test methods. Nitrogen adsorption isotherms were measured at $-196^{\circ} \mathrm{C}$ on an ASAP 2010 volumetric analyzer (Micromeritics, Inc., Norcross, GA, USA). Prior to adsorption measurements, all samples were out gassed under vacuum at $200^{\circ} \mathrm{C}$ for $2 \mathrm{~h}$. BET surface area was also determined by an ASAP 2010 volumetric analyzer (Micromeritics, Inc., Norcross, GA, USA) and the morphological and surface chemistry features of the activated carbon were observed with the Scanning Electron Microscope (SEM) and Fourier Transform Infra-Red (FTIR) (Shimatzu IR affinity- 01) spectroscopy analysis. Elementary analysis of active carbon was done by EDX (ZEISS EVO LS 15 SEM with Oxford EDX-electron diffractive $\mathrm{X}$ ray.). Adsorption studies were carried out batch wise and adsorption measurements were obtained by UV-spectrophoto meter (Shimadzu1800, Japan) at $645 \mathrm{~nm}$.

\section{Specific Surface Area and Porosity Calculations}

The single-point pore volume (Vsp) was estimated from the amount adsorbed at a relative pressure $(\mathrm{p} / \mathrm{po})$ of $\sim 0.98$. The Brunauer-Emmett-Teller specific surface areas (SBET) was calculated from the $\mathrm{N}_{2}$ adsorption isotherms in the relative pressure range of 0.05-0.20 using a cross sectional area of $0.162 \mathrm{~nm}^{2}$ per nitrogen molecule. Pore Size Distributions (PSD) were calculated from adsorption branches of nitrogen adsorption-desorption isotherms using the 2DNLDFT Heterogeneous Surface model for carbon materials implemented in SAIEUS program provided by Micromeritics $[17,18]$ The cumulative pore volume of micropores, (pores below $2 \mathrm{~nm}$ ) was calculated on the basis of the PSD curves obtained by the DFT software.

\section{Preparation of Methylene Blue Solution}

For adsorption characteristics of methylene blue $\left(\mathrm{C}_{16} \mathrm{H}_{18} \mathrm{ClN}_{3} \mathrm{~S}\right)$ on biochar, a mass of $0.008 \mathrm{~g}$ of methylene blue (molar mass = $337.87 \mathrm{~g}$ ) was dissolved in deionized water and finally volume up to $1000 \mathrm{~mL}$.

\section{Batch Adsorption Experiment}

Aqueous solutions of methylene blue with initial concentrations $(8 \mathrm{mg} / \mathrm{L})$ were prepared. $0.3 \mathrm{~g}$ of BFBC was added into the flask containing $50 \mathrm{~mL}$ of the prepared methylene blue solutions and stirred at $27 \pm 1^{\circ} \mathrm{C}$ at the rate of $700 \mathrm{rpm}$. One $\mathrm{mL}$ from the solution was withdrawn at regular time intervals and biochar from the solution was separated immediately by using the micro centrifuge 
operating at $6000 \mathrm{rpm}$ for $10 \mathrm{~min}$. The final concentration of MB in the solution was determined by UV- Visible spectrophotometric analysis and the adsorption capacity of MB on BFBC was determined.

\section{Results and Discussion}

\section{Textural Characterization by Scanning Electron Microscopy (SEM) Analysis}

Scanning Electron Microscopy (SEM) was used to observe the morphology of raw Beli fruit shells, activated carbon produced by phosphoric acid activation. EDX results were used for elemental analysis of Beli fruit activation steps. SEM micrographs of raw Beli shells indicate its surface heterogeneity (Figure 1). roughness and hidden porous structure before chemical treatment. Due to formation of carbonized product as an intermediate in the char activation experiments, the structural changes in the surface morphology of char was seen. After carbonization at $360^{\circ} \mathrm{C}$ formation or waves and pits occurred on the surface of the material. Figures $2 \mathrm{a} \& 2 \mathrm{~b}$ shows the development of porosity and swelling the surface because of the removal of the tarry substances from the internal structure. Also, it gives the acidic nature to the surface [10]. Therefore, the pyrolysis step, followed by suitable washing process removed the excess contaminants from BFAC surface and sponge-like porous surface morphology was seen in Figure 2c. The significant of this activation compared to other methods is due to low-temperature profile and shorter time duration. The EDX results confirm the release of volatile material remarkably from carbon. Micrographs belong to the activated carbon produced by char activation method with phosphoric acid yielded BET surface area of $517 \mathrm{~m}^{2} / \mathrm{g}$. Such a high porous nature of BF activated carbon claims as an efficient adsorbent towards pollutants.

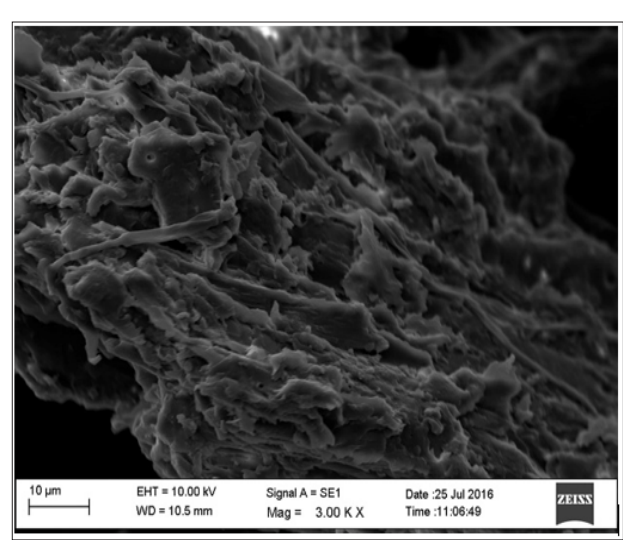

Figure 1: SEM Micrograph of Raw Beli powder.

The molecular nature of the $\mathrm{BF}$ activated carbon surface was analyzed by FTIR spectroscopy (Figure 3). Since activated BF carbon is composed of silicon, the FTIR spectral data should show absorption due to $\mathrm{Si}-\mathrm{O}-\mathrm{Si}$ bonding and these peaks are located at the wavelength around $\sim 499.56 \mathrm{~cm}^{-1}$ [19]. The polysaccharide cellulose which fundamentally comprises of several D-glucose units showed prominent characteristic peaks of $\mathrm{O}-\mathrm{H}, \mathrm{C}-\mathrm{O}$, and glycosidic linkages. The peaks at $2890 \mathrm{~cm}^{-1}$ and $3372 \mathrm{~cm}^{-1}$ could be attributed to the $\mathrm{C}-\mathrm{H}$ and $\mathrm{O}-\mathrm{H}$ stretching, respectively [20]. Absorption at $1672 \mathrm{~cm}^{-1}$ is the result of vibration of carbonyls $(\mathrm{C}=0)$ in the amide bond.

\section{Thermogravimetry (TG) and Differential Thermogravi- metry (DTG) Studies}

Thermal stability of the activated carbon samples was analyzed by using high-resolution Thermogravimetry (TG) and Differential Thermogravimetry (DTG) profiles (Figure 4) in the temperature window of 25 to $800^{\circ} \mathrm{C}$ under nitrogen atmosphere. Two thermal events were observed on the DTG profile at $20-150^{\circ} \mathrm{C}$ and 390 $550^{\circ} \mathrm{C}$. The insignificant first peak of AC samples is responsible for evaporation of physically adsorbed water. Peak observed at 390$550^{\circ} \mathrm{C}$ pertains to the decomposition of cellulose groups [21-23]. However, decomposition

\section{$\mathbf{N}_{2}$ Adsorption Analysis}

Nitrogen adsorption-desorption isotherms was measured at $-196^{\circ} \mathrm{C}(77 \mathrm{~K})$ for PFAC, CSAC, BFAC, and CAAC samples. PFAC and CSAC do not show significant adsorption isotherms (not shown here) and hence surface properties are significantly lower (Table 2). Adsorption-desorption isotherms measured for BFAC, and CAAC samples are shown in Figure 5.

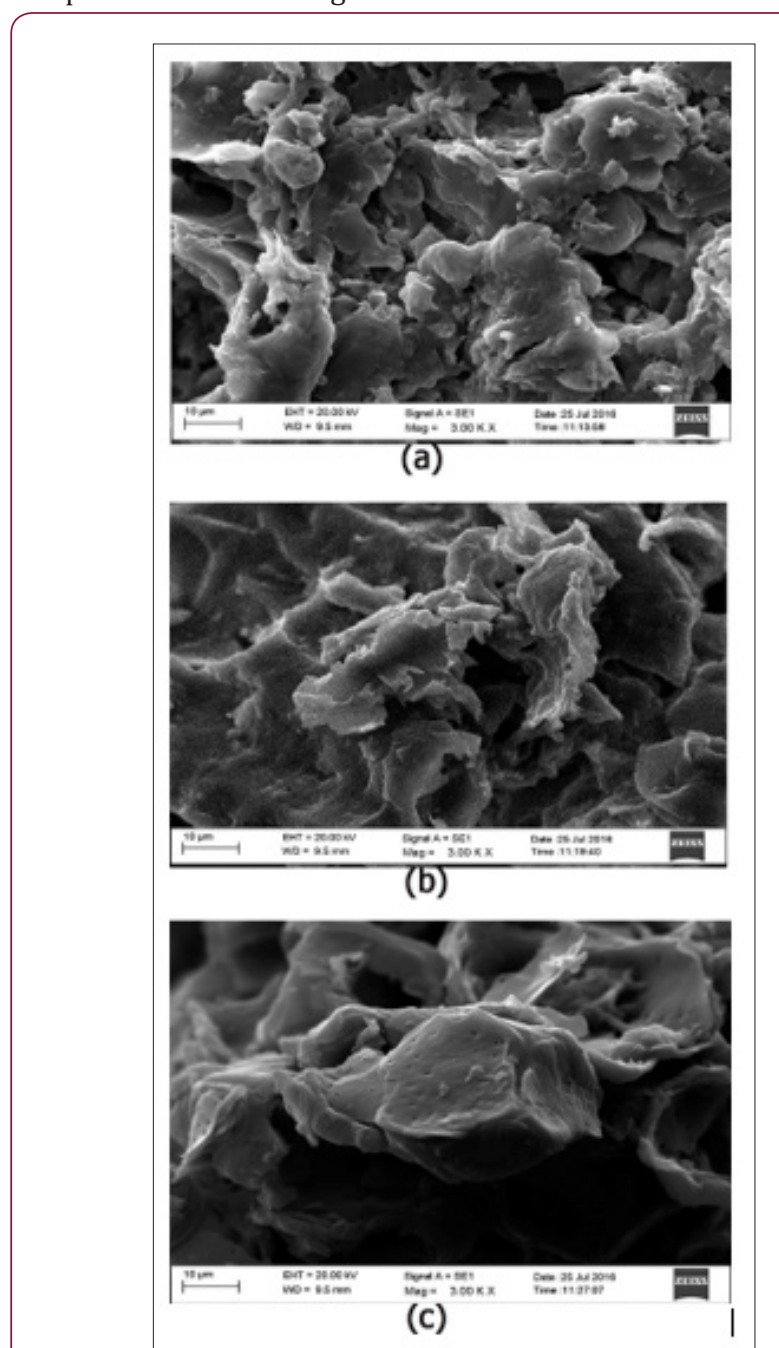

Figure 2: SEM Micrographs for (a) raw fiber treated with $\mathrm{H}_{3} \mathrm{PO}_{4}(\mathrm{~b})$ unwashed BFAC (c) BFAC after washing. 


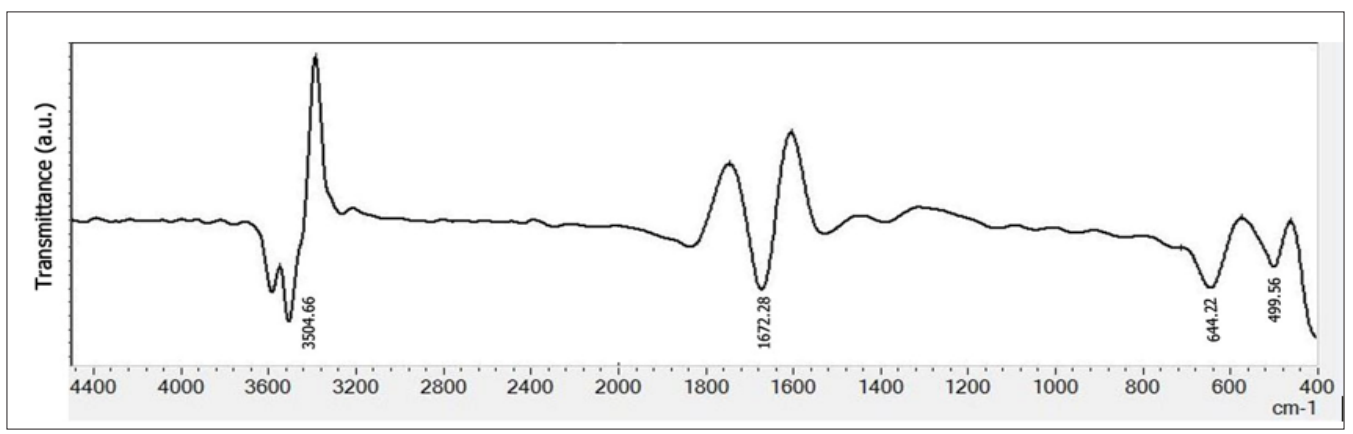

Figure 3: FTIR Spectrum for BFBC.
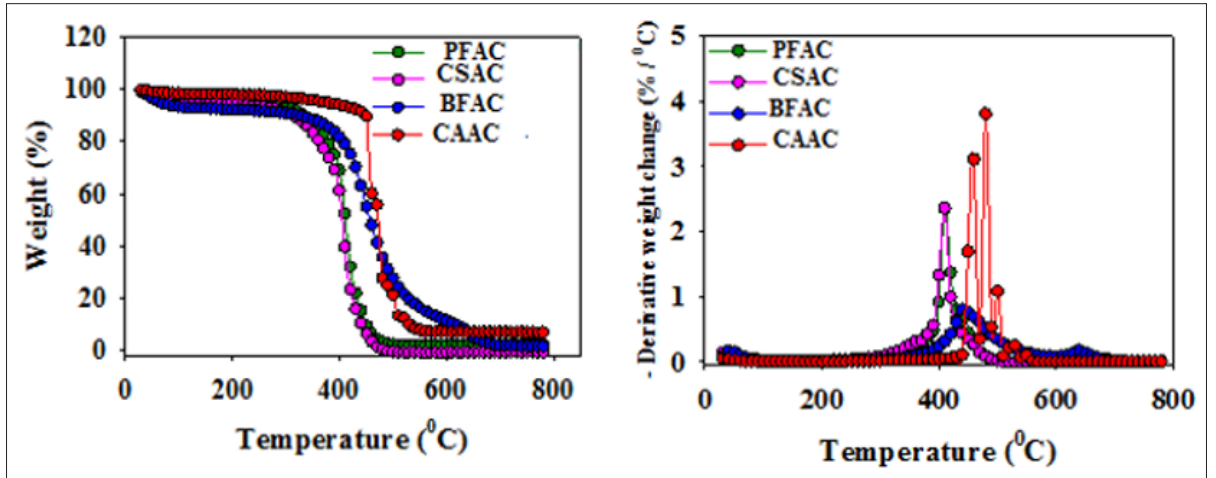

Figure 4: TG (left) and DTG (right) profiles for the PFAC, CSAC, BFAC, and CAAC samples temperature of BFAC sample has shifted to higher temperature range $\left(400-600^{\circ} \mathrm{C}\right)$. Weight change $(\%)$ was calculated based on the decomposition peak observed in TG profile for AC samples in their corresponding temperature range. Residue percentage was also calculated for those samples at $800^{\circ} \mathrm{C}$. Those results were tabulated in Table 2. It is interesting to observe that all samples are decomposed more than $90 \%$ during the temperature range of $390-550^{\circ} \mathrm{C}$ and small amount of sample was left at $800^{\circ} \mathrm{C}$.

Table 2: Weight change (\%) and Residue (\%) calculated for PFAC, CSAC, BFAC, and CAAC samples.

\begin{tabular}{|c|c|c|}
\hline Sample & Weight change \% & Residue \% \\
\hline PFAC & 97.60 & 2.40 \\
\hline CSAC & 99.47 & 0.53 \\
\hline BFAC & 98.26 & 1.74 \\
\hline CAAC & 93.04 & 6.96 \\
\hline
\end{tabular}

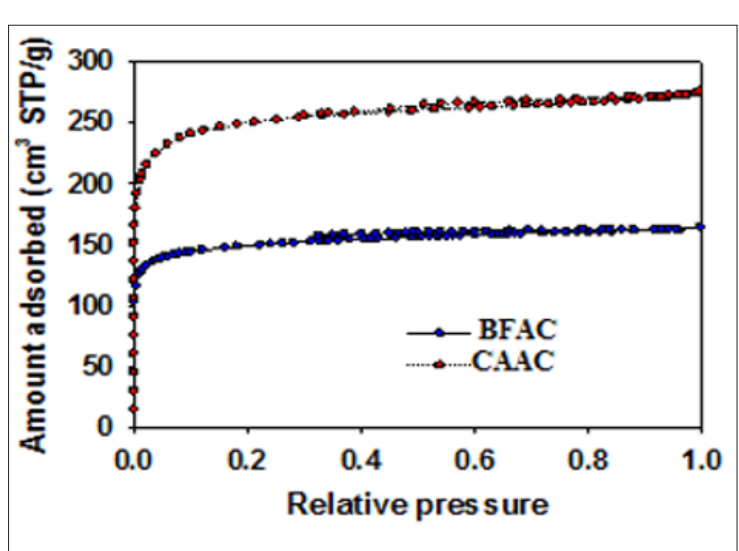

Figure 5: Nitrogen adsorption-desorption isotherm curves for BFAC and CAAC samples.
Nitrogen adsorption isotherm for the BFAC, and CAAC samples display a type I isotherm with significant amount of $\mathrm{N}_{2}$ adsorption at low relative pressure region $(<0.01)$ with plateau at high relative pressure region characteristic for microporous materials. However, absence of distinct hysteresis loop for these two isotherms indicate the nonexistence of mesoporous. Adsorption parameters such as the single Point Pore Volume (Vsp), Specific Surface Area (SBET), Micropores Volume (Vmi), Total Pore Volume (Vt), and Monolayer Capacity (MLC) were calculated using nitrogen adsorptiondesorption isotherms and listed in Table 3. As can be seen from the Table 3, PFAC and CSAC samples show significantly lower adsorption properties as compared with BFAC and CAAC samples. For instance, PFAC sample displays micropores volume and surface area of $0.006 \mathrm{~cm}^{3} / \mathrm{g}$ and $6 \mathrm{~m}^{2} / \mathrm{g}$, respectively, and these values are increased to $0.16 \mathrm{~cm}^{3} / \mathrm{g}$ and $517 \mathrm{~m}^{2} / \mathrm{g}$ for BFAC sample.

Table 3: Structural parameters and adsorption values obtained for the PFAC, CSAC, BFAC, and CAAC samples.

\begin{tabular}{|c|c|c|c|c|c|}
\hline Content & Vsp (cc/g) & $\begin{array}{c}\text { Vmic } \\
(\mathbf{c c} / \mathbf{g})\end{array}$ & $\begin{array}{c}\text { SBET } \\
\left(\mathbf{m}^{2} / \mathbf{g}\right)\end{array}$ & $\begin{array}{c}\text { MLC (CC } \\
\mathbf{S T P} / \mathbf{g})\end{array}$ & $\mathbf{V t}(\mathbf{c c} / \mathbf{g})$ \\
\hline PFAC & $<0.01$ & $<0.01$ & 6 & 1.4 & $<0.01$ \\
\hline CSAC & $<0.01$ & $<0.01$ & $<1$ & $<1$ & $<0.01$ \\
\hline BFAC & 0.20 & 0.16 & 517 & 119 & 0.25 \\
\hline CAAC & 0.38 & 0.29 & 865 & 199 & 0.42 \\
\hline
\end{tabular}


Note: $\mathrm{V}_{\mathrm{sp}}$-single point pore volume calculated at the relative pressure of 0.98; $\mathrm{V}_{\text {mic }}$-volume of fine pores (micropores $<2$ $\mathrm{nm}$ ) calculated by integration of the PSD curve up to $2 \mathrm{~nm}$ obtained DFT method; $\mathrm{S}_{\mathrm{BET}}$-specific surface area calculated from adsorption data in relative pressure range of $0.05-0.20$; MLCmonolayer capacity; Vt-total pore volume (micropores and small mesopores below $10 \mathrm{~nm}$ ) calculated by integration of the PSD curve up to $10 \mathrm{~nm}$.

Significant $\mathrm{N}_{2}$ adsorption isotherm for the materials PFAC and CSAC could not be achieved due to its extremely low porous nature. Enlargement of surface properties was observed from BFAC sample to CAAC sample. For instance, the BFAC sample exhibits the micropore volume, total pore volume, and surface area of 0.16 $\mathrm{cm}^{3} / \mathrm{g}, 0.42 \mathrm{~cm}^{3} / \mathrm{g}$, and $517 \mathrm{~m}^{2} / \mathrm{g}$, respectively, and these values are increased to $0.29 \mathrm{~cm}^{3} / \mathrm{g}, 0.42 \mathrm{~cm}^{3} / \mathrm{g}$, and $865 \mathrm{~m}^{2} / \mathrm{g}$ CAAC sample. The nitrogen uptake for CAAC is increased at low pressure region, indicating an increase in the volume of micropores as compared to BFAC sample. Density Functional Theory (DFT) software was used to calculate the pore size distributions for BFAC and CAAC. Figure 6 displays the Pore Size Distribution (PSD) curves for the BFAC and CAAC samples studied. As can be seen from the Figure 6, The PSD curve for BFAC and CAAC clearly indicate the presence of large amount of micro porosity $(<2 \mathrm{~nm})$ as compared with that for PFAC and CSAC samples.

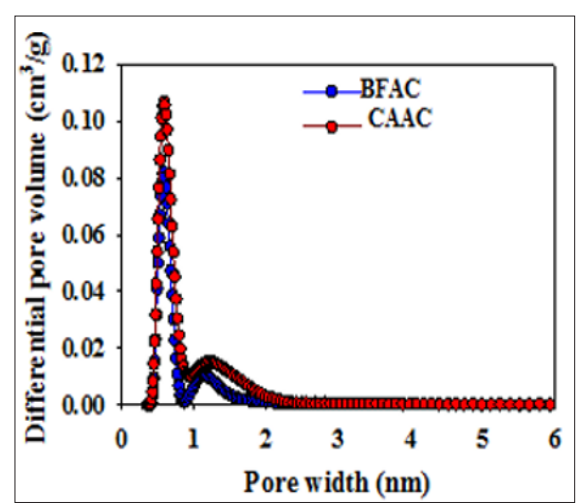

Figure 6: PSD curves for BFAC and CAAC samples.

\section{Potential of Zero Charge Measurement}

The Potential of zero charge of Beli Fruit Shell Charcoal (BFAC) was determined by a surface titration technique with an Auto titrator at room temperature. The measurements were performed with $0.05 \mathrm{~g}$ of BFAC dispersed in $0.1 \mathrm{M} \mathrm{NaCl}$ solution and adjusting the initial $\mathrm{pH}$ to 10.0 by $0.1 \mathrm{M} \mathrm{NaOH}$ followed by a titration with $0.1 \mathrm{M} \mathrm{HCl}$ until the $\mathrm{pH}$ reaches to 2.0 . Titration was repeated for $0.01 \mathrm{M}$ and $0.001 \mathrm{M} \mathrm{NaCl}$ solutions. The net surface proton charge density $\sigma$ for each titration was calculated by the following equation [24]:

$$
\sigma=\left\{\mathrm{C}_{A}-\mathrm{C}_{B}-\left[\mathrm{H}^{+}\right]+\left[\mathrm{OH}^{-}\right]\right\} \frac{F}{A \cdot b}
$$

where $\sigma$ is the surface charge density, CA and CB are the equivalent acid and base added during titration; $\left[\mathrm{H}^{+}\right]$and $\left[\mathrm{OH}^{-}\right]$are the concentrations of $\mathrm{H}^{+}$and $\mathrm{OH}^{-}$in the bulk solution; $\mathrm{F}$ is the Faraday constant; A is the surface area; and b is the solid concentration in grams per liter. It was found graphically in the plot of $\sigma \mathrm{vs} \mathrm{pH}$, that $\mathrm{pH}$ is 3.35 at which the net charge on the surface is zero which suggests that surface is negatively charged above $\mathrm{pH} 3.35$.

\section{Effect of Adsorbent Dose}

The Effect of adsorbent dose on the removal of the dye from aqueous solution was studied using an absorbent dose of BFAC 20$100 \mathrm{mg}$. Adsorbent dosage Vs methylene blue (Figure 7) removal efficiency is shown in Figure 8. It clearly shows that removal efficiency enhanced as the dose increased from 20-60 mg. As the activated carbon dose increases, surface area and more available adsoption sites are increased in the solution [16]. Further increased in dose into solution did not significantly change the removal efficiency. Because all adsorption sites have been reached to an equilibrium level. Therefore, $30 \mathrm{mg} / \mathrm{L}$ adsorbent dose was selected for the subsequent experiments.

\section{Effect of $\mathbf{p H}$}

The effect of solution $\mathrm{pH}$ on the adsorption of dye is shown in Figure 9 for BFAC. The amount of adsorption increases when the $\mathrm{pH}$ increased. Higher $\mathrm{pH}$ was found to be favorable for maximum removal efficacy and consistent with the results obtained for surface charged measurement. The negatively charged carbon surface functional groups at $\mathrm{pH}$ greater than 3.35 could electrostatically interact with methylene blue cations.

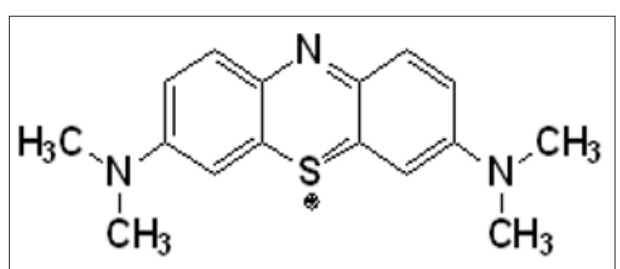

Figure 7: Structure of methylene blue cation.

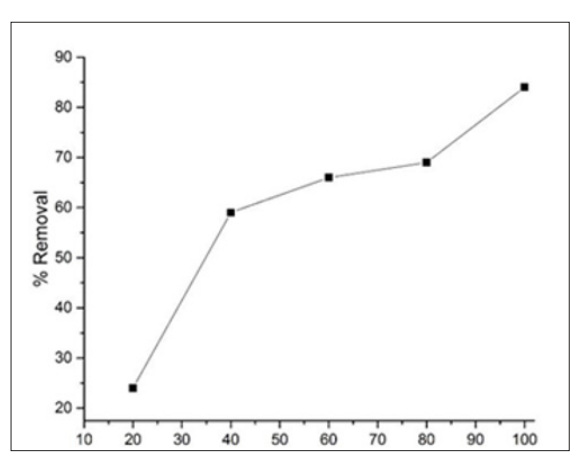

Figure 8: Effect of adsorbent dose on methylene blue removal.

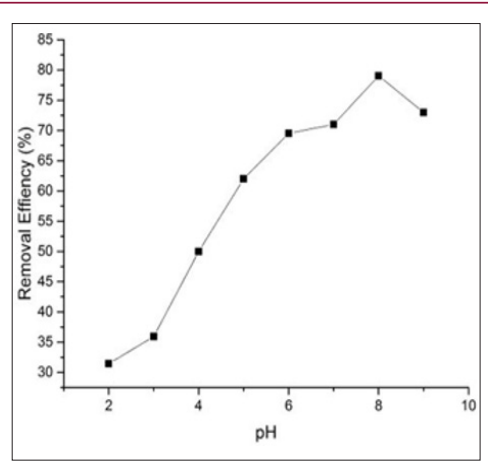

Figure 9: Dependance of removal efficency at different $\mathrm{pH}$. $(\mathrm{rpm}=700$; concentration $=10.5 \mathrm{mg} / 1$; time $=30 \mathrm{~min}$; temperature $=27^{\circ} \mathrm{C}$; volume $\left.=50 \mathrm{ml}\right)$. 


\section{Adsorption Isotherm}

Equilibrium Adsorption Measurements for Dye: Several solutions of dye with different initial concentration $(10.8 \mathrm{mg} / \mathrm{L}$, $3.8 \mathrm{mg} / \mathrm{L}, 2.65 \mathrm{mg} / \mathrm{L}$, and $1.05 \mathrm{mg} / \mathrm{L}$ ) were prepared for the study of equilibrium adsorption. $50 \mathrm{~mL}$ of dye solution with $0.3 \mathrm{~g}(\mathrm{~V} /$ $\mathrm{m}=500 / 3$ ) of the BFAC were placed under stirring $\left(700 \mathrm{rpm}, 27^{\circ} \mathrm{C}\right.$, $\mathrm{pH}=7$ ) for 30 minutes. The amount of adsorbed dye per unit mass of the solid (Beli powder) at equilibrium, $\left(\mathrm{q}_{\mathrm{e}}\right)$, was calculated by the following equation:

$$
q_{e}=\frac{\left(C_{o}-C_{e}\right) V}{m}
$$

Where $\mathrm{C}_{0}(\mathrm{mg} / \mathrm{L})$ is the initial concentration of dye, $\mathrm{V}(\mathrm{mL})$ the volume of dye solution and $\mathrm{m}(\mathrm{g})$ of the adsorbent mass. $\mathrm{C}_{\mathrm{e}}(\mathrm{mg} / \mathrm{L})$ is the dye concentration at equilibrium.

\section{Kinetic Adsorption Experiments for Dye}

Kinetic adsorption experiments were carried out using the initial dye concentration of $10.5 \mathrm{mg} / \mathrm{L}$ of the modified BFAC were placed under similar experimental conditions as those used in equilibrium measurements (700 rpm stirring, $27^{\circ} \mathrm{C}, \mathrm{pH}=7$ ). 0.5 $\mathrm{mL}$ of solution was withdrawn before mixing the adsorbent and dye ion solution $(\mathrm{t}=0)$ and at pre- determined intervals $(\mathrm{t}=2 \mathrm{~min}$ to $t=30$ minutes). The amount of adsorbed dye per unit mass of the substrate at time $t,\left(q_{t}\right)$, was calculated by the following equation:

$$
q_{t}=\frac{\left(C_{o}-C_{t}\right) V}{m}
$$

where $\mathrm{C}_{\mathrm{t}}(\mathrm{mg} / \mathrm{L})$ is the concentration of dye at a given time, and other symbols have the same meaning as above.

\section{Equilibrium Adsorption Data Analysis}

Langmuir isotherm equation can be used to analyze equilibrium adsorption data. 'Following assumptions were basically used in Langmuir adsorption model 1) all sites are identical and energetically equivalent 2) no lateral interactions, and 3 ) adsorption is limited to the formation of monolayer only. ${ }^{25}$ Based on the Langmuir model, adsorption of dye on the BFAC substrate can be expressed as;

$$
q_{e}=\frac{K_{l} C_{e} q_{m}}{1+K_{l} C_{e}}
$$

where $K_{l}$ is the Langmuir constant, $\mathrm{C}_{\mathrm{e}}$ is the equilibrium concentration, $q_{m}$ and $q_{e}$ are the maximum and equilibrium adsorbed quantities, respectively. Experimental data were fitted to the Langmuir equation using non-linear regression to obtain the values of $K_{l}$ and $q_{m}$. The linear form of the above Langmuir equation can be expressed as follows:

$$
\frac{C_{e}}{q_{e}}=\frac{C_{e}}{q_{m}}+\frac{1}{K_{l} q_{m}}
$$

By plotting $\frac{C_{e}}{q_{e}}$ verses $\mathrm{C}_{\mathrm{e}^{\prime}}$ it is possible to calculate the aforementioned $q_{m}^{q_{e}}$ and $K_{l}$ parameters and validate the curve fitting value $\left(\mathrm{R}^{2}\right)$.

Adsorption isotherm is used to calculate the theoretical adsorption capacity for a given adsorbent. The Langmuir and Freundlich isotherm models used for this work are the common models that are applied for liquid phase applications $[18,26]$.
Normally organic or heavy metal substance is bound onto activated carbon surface by physisorption or chemisorption. The concentration of adsorbate remaining in the effluent at the equilibrium depends on the type of activated carbon. Figure 10 display the nonlinear Langmuir regression curve.

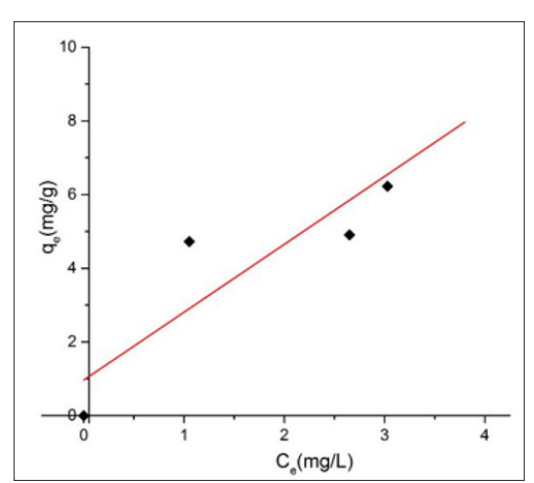

Figure 10: Adsorption isotherms for Methylene Blue on BFAC.

Figures 11 \& 12 show the Langmuir and Freundlich adsorption models for BFAC respectively. Data of Langmuir and Freundlich isotherm parameters for adsorption of $\mathrm{MB}$ on carbon samples clearly show that all the chemically prepared activated carbon showed higher regression coefficient value in the Langmuir isotherm compared to Freundlich isotherm (Table 4). But activated carbon was best fitted to Langmuir isotherm with the highest regression coefficient $\left(\mathrm{R}^{2}=0.91663\right)$ (Table 4$)$.

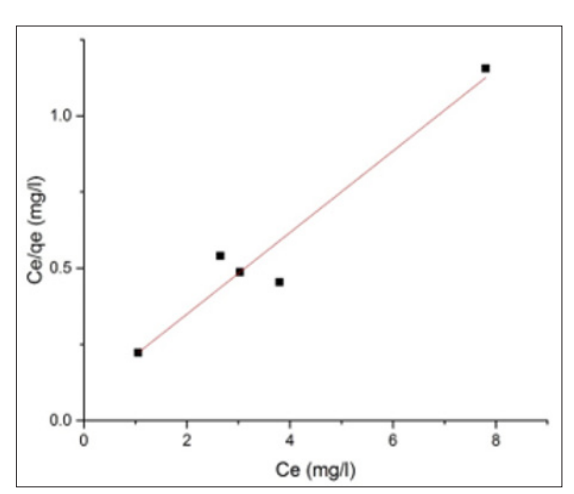

Figure 11: Adsorption isotherms for Methylene Blue on BFAC.

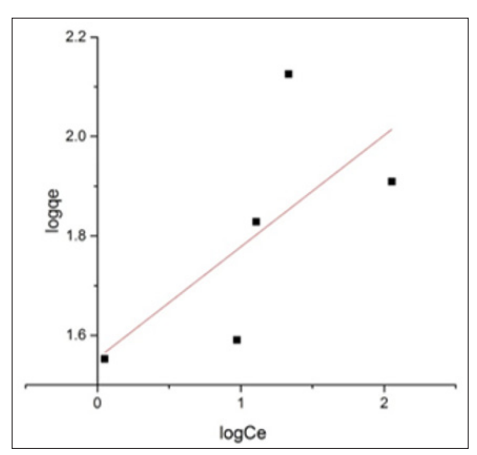

Figure 12: Freundlich plots for the adsorption of $\mathrm{MB}$ dye on BFAC 
Table 4: Regression coefficients values determined for Langmuir and Freundlich models.

\begin{tabular}{|c|c|}
\hline Isotherm model & Regression coefficient $\mathbf{( R}^{\mathbf{}} \mathbf{)}$ \\
\hline Langmuir & 0.916 \\
\hline Freundlich & 0.714 \\
\hline
\end{tabular}

The Langmuir maximum monolayer capacity value achieved in this study was compared with other results reported in the literature (Table 5). As can be seen from Table 5, activated carbon produced from Beli-shell show significantly higher MB adsorption. It adsorbed $12.32 \mathrm{mg}$ of MB per gram of activated carbon (produced from Beli-shell) which is comparably higher than that of values reported in literature.

Table 5: Comparison of Maximum mono layer capacity of MB dye onto different activated carbon samples.

\begin{tabular}{|c|c|c|c|}
\hline Dyes & $\begin{array}{c}\text { Adsorbent type } \\
\text { Activated carbon }\end{array}$ & $\begin{array}{c}\text { Maximum } \\
\text { Capacity } \\
\text { (mg/g) }\end{array}$ & References \\
\hline Methylene blue & Beli shell & 12.32 & This study \\
\hline Congored & Coir pith & 6.72 & {$[34]$} \\
\hline Methylene blue & Jute fiber & 225.64 & {$[33]$} \\
\hline Methylene blue & Almond shell & 1.33 & {$[21]$} \\
\hline Methylene blue & Walnut shell & 3.53 & {$[21]$} \\
\hline Methylene blue & Hazelnut shell & 8.82 & {$[21]$} \\
\hline Methylene blue & Apricot stones & 4.11 & {$[21]$} \\
\hline
\end{tabular}

\section{Adsorption Kinetics}

Models used to Analyze Adsorption Kinetics Data: Adsorption kinetics data were fitted and analyzed by using two most popular models. The first order adsorption kinetics model proposed by Lagergren ${ }^{27}$ and developed by Krishnan [28] described as follows:

$$
\frac{d q}{d t}=K_{1}\left(q_{e}-q_{t}\right)
$$

Where $q_{e}$ and $\mathrm{q}_{\mathrm{t}}$ are the amount of adsorbed metal ions at the equilibrium and time $t$, respectively. $K_{1}$ is the rate constant of the first order adsorption reaction. Integration of the above equation at time $=0$ and time $=$ t gives:

$$
\log \left(q_{e}-q_{t}\right)=\frac{-K_{1} t}{2.303}+\log q_{e}
$$

Plotting $\log \left(q_{e}-q_{t}\right)$ verses t can be used to find $K_{1}$. The pseudo second order kinetic model suggested by Ho and Mckay ${ }^{29}$ can be stated by following equation:

$$
\frac{d q}{d t}=K_{2}\left(q_{e}-q_{t}\right)^{2}
$$

Where $K_{2}$ is the pseudo second order rate constant of adsorption $\left(\mathrm{g} \mathrm{mg}^{-1} \mathrm{~min}^{-1}\right)$. The integrated linear form of the above equation is:

$$
\frac{t}{q_{t}}=\frac{1}{K_{2} q_{e}^{2}}+\frac{t}{q_{e}}
$$

$K_{2}$ and $q_{e}$ can be easily found from the slope and intercept of the plot $\frac{t}{q}$ verses t.

\section{Adsorption Kinetics Data Analysis}

The study of the adsorption kinetics is important to evaluate the mechanism and efficiency of effluents adsorption method
[30]. The kinetics of adsorption of MB by BFAC were analyzed using pseudo-first-order pseudo-second -order kinetic models and intraparticle diffusion (Figures 13-15). It was revealed that the adsorption of BFAC was best fitted to pseudo-second -order kinetic model as indicated by the $\mathrm{R}^{2}$ value of 0.99901 (Figure 14) compared to pseudo-first -order kinetic models $\left(\mathrm{R}^{2}=0.987147\right)$. The confirmation of pseudo-second -order kinetic models suggest that adsorption of MB on BFAC is due to chemisorption. ${ }^{24}$ Pseudosecond-order model rate constant for BFAC was calculated to be $0.12284 \mathrm{~min}^{-1}$ at $30^{\circ} \mathrm{C}$. The chemisorption process involved a sharing electron between MB and the surface of activated carbon. Although it might be followed by the supplementary layer of physically adsorbed dye molecules, it is controlled to just one of dye molecule on the surface in chemisorption. Similar adsorption kinetics have been obtained from adsorption of MB by different low-cost precursor [31-33].

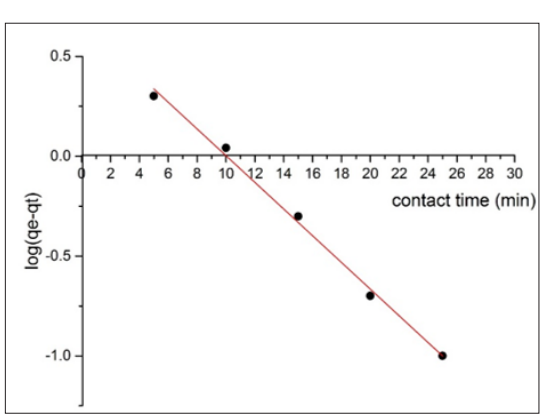

Figure 13: Pseudo-first-order kinetics model plots for the adsorption of $\mathrm{MB}$ dye on BFAC: $(\mathrm{pH}=7 \quad \mathrm{rpm}=700$ concentration $=8 \mathrm{mg} / 1$ time $=30 \mathrm{~min}$ temperature $=27 \mathrm{oC}$, volume $=50 \mathrm{ml})$.

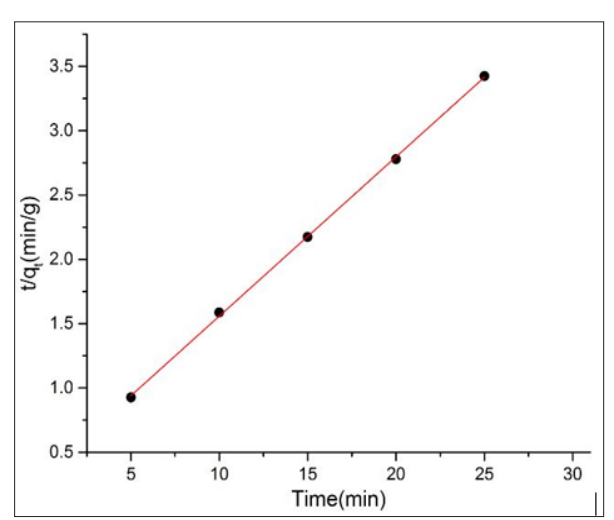

Figure 14: Pseudo- second- order kinetics model plots for the adsorption of MB dye on Beli activated carbon:( $\mathrm{pH}=7 \mathrm{rpm}=700$ concentration $=10.5 \mathrm{mg} / 1$ time $=30 \mathrm{~min}$ temperature $=27 \mathrm{oC}$, volume $=50 \mathrm{ml}$ ).

Adsorption process related the transport of carbon matter from the bulk solution to the interior surface of the pore, rate of adsorption control by solution stirrer parameter such as speed, contact time etc.

Intra-particle diffusion for dye determined using the following equation

$$
q_{t}=k_{p} t^{1 / 2}
$$


Where $\mathrm{k}_{\mathrm{p}}$ is the intraparticle diffusion rate constant. The plot (Figure 15) clearly consists of two main portions, which is initial portion and the linear portion. But the linear portion of the curve reviles intraparticle diffusion. All adsorption process is controlled by Intra-particle diffusion. According to calculation of this system intraparticle diffusion rate is $0.3333 \mathrm{mg} / \mathrm{g} \mathrm{min}^{1 / 2}$.

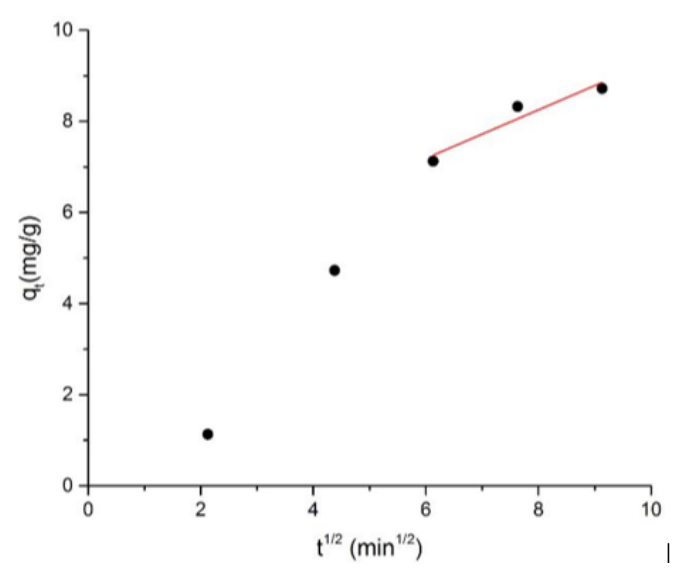

Figure 15: Inter particle diffusion rate kinetics plots for the adsorption of $\mathrm{MB}$ dye on BFAC: $\mathrm{pH}=7 \quad \mathrm{rpm}=700$ concentration $=10.5 \mathrm{mg} / 1$ time $=30 \mathrm{mn}$ temperature $=27 \mathrm{oC}$, volume $=50 \mathrm{ml}$ ).

\section{Conclusion}

The present study shows that the biobent beli shell activated carbon can be remarkably used as an adsorbent for the removal of methylene blue from textiles effluents. The kinetic data were well fitted by second order kinetics model the equilibrium dye uptake (mg/g) was found to decrease with increase in BFAC entering biosorption process was found to be surface controlled. Best fit of isotherm data in Langmuir model relation confirm the monolayer sorption of MB on BFAC.

\section{Acknowledgment}

National Research Council of Sri Lanka (NRC) and the university Grant Commission of Sri Lanka are acknowledged for providing the equipment grants for this research program.

\section{References}

1. Charerntanyarak L (1999) Heavy metals removal by chemical coagulation and precipitation. Water Sci Technol 39(10): 135-138.

2. Fenglian Fu, Qi Wang (2011) Removal of heavy metal ions from wastewaters: A review. J Environ Manage 92(3): 407-418.

3. Robinson T, McMullan, G Marchant R, Nigam P (2001) Remediation of dyes in textile effluent: A critical review on current treatment technologies with a proposed alternative. Bioresour Technol 77(3): 247255.

4. Osmond N M (2007) Activated carbon fibre adsorbent materials. Adsorpt Sci Technol 18(6): 529-539.

5. Carrott P J M, Carrott M R (2006) Lignin-from natural adsorbent to activated carbon: A review. Bioresour Technol 98(12): 2301-2312.

6. Evita Agrafioti, Dimitrios Kalderis, Evan Diamadopoulos (2014) Arsenic and chromium removal from water using biochars derived from rice husk, organic solid wastes and sewage sludge. J Environ 133: 309-314.
7. Dong X, Ma LQ Li Yuncong (2011) Characteristics and mechanisms of hexavalent chromium removal by biochar from sugar beet tailing. J Hazard 1(3): 909-915.

8. Mohan D, Pittman C U, Bricka M, Smith F Yancey, B Mohammad, et al. (2007) Sorption of arsenic, cadmium, and lead by biochar produced from fast pyrolysis of wood and bark during bio-oil production. J Colloid Interface Sci 310: 57-73.

9. Molina Sabio M, Rodrıguez Reinoso F (2004) Role of chemical activation in the development of carbon porosity. Colloids and Surfaces A: Physicochem Eng Aspects 241(1): 15-25.

10. Girgis BS, El Hendawy AN A (2002) Porosity development in activated carbons obtained from date pits under chemical activation with phosphoric acid. Microporous mesoporous mater 52(2): 105-117.

11. Hui TS, Zaini MA (2015) Potassium hydroxide activation of activated carbon: A commentary. Carbon Lett 16(4): 275-280.

12. Wang SL, Lee JF (2011) Reaction mechanism of hexavalent chromium with cellulose. Chem Eng J 174(1): 289-295.

13. Jagiello J, Olivier J P (2013) Carbon slit pore model incorporating surface energetical heterogeneity and geometrical corrugation. Adsorpt $19(2-$ 4): 777-783.

14. Fletcher A J, Uygur Y, Thomas K M (2007) Role of surface functional groups in the adsorption kinetics of water vapor on microporous activated carbons. J Phys Chem C 111(23): 8349-8359.

15. Jagiello J, Olivier J P (2013) 2D-NLDFT adsorption models for carbon slitshaped pores with surface energetical heterogeneity and geometrical corrugation. Carbon 55: 70-80.

16. Nair R, Barche S (2016) Medicinal value of Bael, Aegle marmelos. Int J Farm Sci 6(1): 307-320.

17. Liu R, Zhang B, Mei D, Zhang H, Liu J (2011) Adsorption of methyl violet from aqueous solution by halloysite nanotubes. Desalination 268(1): 111-116.

18. Kannan N, Sundaram MM (2001) Kinetics and mechanism of removal of methylene blue by adsorption on various carbons. Dyes and Pigm 51(1): 25-40.

19. Hou S, Su S, Kasner M L, Shah P, Patel K, et al. (2010) Formation of highly stable dispersions of silane-functionalized reduced graphene oxide. Chem Phys Lett 501(1): 68-74.

20. Jindo K, Mizumoto H, Sawada Y, Sanchez-Monedero MA, Sonoki T (2014) Physical and chemical characterization of biochar derived from different agricultural residues. Biogeosci 11(23): 6613-6621.

21. Chamila Gunathilake, Rohan S. Dassanayake, Noureddine Abidi, Mietek Jaroniec (2016) Amidoxime-functionalized microcrystalline cellulosemesoporous silica composites for carbon dioxide sorption at elevated temperatures. J Mater Chem 4(13): 4808-4819.

22. Rohan S Dassanayake, Chamila Gunathilake, Tanya Jackson, Mietek Jaroniec, Noureddine Abidi (2016) Preparation and adsorption properties of aero cellulose-derived activated carbon monoliths. Cellulose 23(2): 1363-1374.

23. Rohan S Dassanayake, Chamila Gunathilake, Arosha C Dassanayake, Noureddine Abidi, Mietek Jaroniec (2017) Amidoxime-functionalized nanocrystalline cellulose-mesoporous silica composites for carbon dioxide sorption at ambient and elevated temperatures. J Mater Chem 5(16): 7462-7473.

24. Morgan JJ, Stumm W (1981) Aquatic Chemistry: An introduction emphasizing chemical equilibria in natural waters. John Wiley \& Sons, New York, USA, pp. 780.

25. Sari A, Tuzen M (2009) Kinetic and equilibrium studies of biosorption of $\mathrm{Pb}$ (II) and Cd (II) from aqueous solution by macrofungus (Amanita rubescens) biomass. J hazard mater 164(2): 1004-1011. 
26. Lagergren Svenska (1898) About the theory of so-called adsorption of soluble substances. Handlingar 24: 1-39.

27. Annadurai G Krishnan MR V (1996) Adsorption of basic dye using chitin. Indian J Environ Protec 16(6): 444-449.

28. Ho YS, McKay G (1999) Pseudo-second order model for sorption processes. Process biochem 34(5): 451-465.

29. McKay G (1982) Adsorption of dyestuffs from aqueous solutions with activated carbon I: Equilibrium and batch contact-time studies. J chem Technol biotechnol 32(7-12): 759-772.

30. Senthilkumaar S, Varadarajan PR, Porkodi K, Subbhuraam CV (2005) Adsorption of methylene blue onto jute fiber carbon: Kinetics and equilibrium studies. J colloid interface sci 284(1): 78-82.

ISSN: 2574-1241

DOI: $10.26717 / B J S T R .2018 .11 .002152$

Gunathilake C. Biomed J Sci \& Tech Res

CC (i) This work is licensed under Creative

BY Commons Attribution 4.0 License

Submission Link: https://biomedres.us/submit-manuscript.php
31. Namasivayam C, Dyes Kavitha (2002) Removal of Congo Red from water by adsorption onto activated carbon prepared from coir pith, an agricultural solid waste. Dyes pigm 54(1): 47-58.

32. Gupta N, Kushwaha AK, Chattopadhyaya MC (2016) Application of potato (Solanumtuberosum) plant wastes for the removal of methylene blue and malachite green dye from aqueous solution. Arabian J Chem 9: S707-S771.

33. Aygüna A, Yenisoy-Karakaşb S, Duman I (2003) Production of granular activated carbon from fruit stones and nutshells and evaluation of their physical, chemical and adsorption properties. Microporous mesoporous mater 66(2): 189-195.

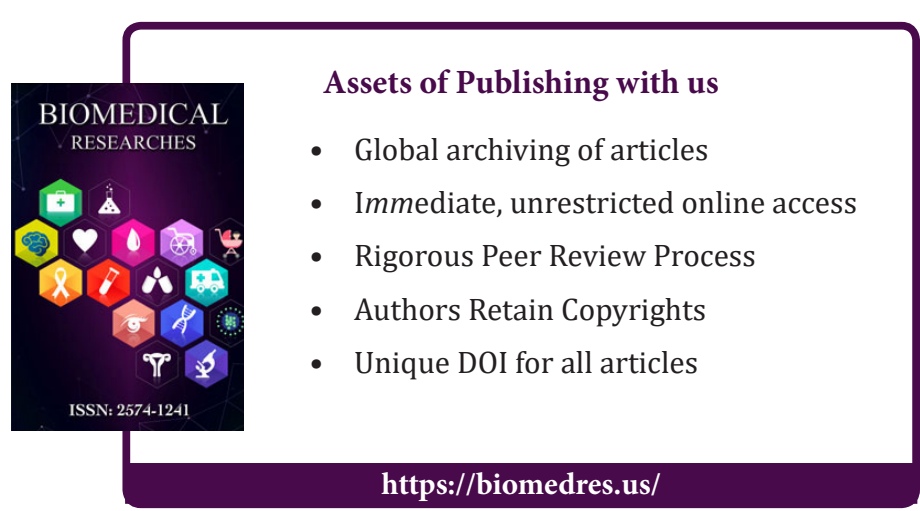

